\title{
Bond Strengths of Geopolymer and Cement Concretes
}

\author{
Prabir Sarker \\ School of Civil and Mechanical Engineering, Curtin University of Technology, Perth, Western \\ Australia \\ p.sarker@curtin.edu.au
}

Keywords: beam end specimen, bond strength, geopolymer concrete, pull-out test.

\begin{abstract}
Geopolymer is an inorganic alumino-silicate product that shows good bonding properties. Geopolymer binders are used together with aggregates to produce geopolymer concrete which is an ideal building material for infrastructures. A by-product material such as fly ash is mixed together with an alkali to produce geopolymer. Current research on geopolymer concrete has shown potential of the material for construction of reinforced concrete structures. Structural performance of reinforced concrete depends on the bond between concrete and the reinforcing steel. Design provisions of reinforced concrete as a composite material are based on the bond strength between concrete and steel. Since geopolymer binder is chemically different from Ordinary Portland Cement (OPC) binder, it is necessary to understand the bond strength between geopolymer concrete and steel reinforcement for its application to reinforced concrete structures. Pull out test is commonly used to evaluate the bond strength between concrete and reinforcing steel. This paper describes the results of the pull out tests carried out to investigate the bond strength between fly ash based geopolymer concrete and steel reinforcing bars. Beam end specimens in accordance with the ASTM Standard A944 were used for the tests. In the experimental program, 24 geopolymer concrete and 24 OPC concrete specimens were tested for pull out. The concrete compressive strength varied from 25 to $55 \mathrm{MPa}$. The other test parameters were concrete cover and bar diameter. The reinforcing steel was $500 \mathrm{MPa}$ steel deformed bars of $20 \mathrm{~mm}$ and $24 \mathrm{~mm}$ diameter. The concrete cover to bar diameter ratio varied from 1.71 to 3.62 . It was found from the test results that the failure occurred by splitting of concrete in the region bonded with the steel bar, in both geopolymer and OPC concrete specimens. Comparison of the test results shows that geopolymer concrete has higher bond strength than OPC concrete. This suggests that the existing design equations for bond strength of OPC concrete with steel reinforcing bars can be conservatively used for calculation of bond strength of geopolymer concrete.
\end{abstract}

\section{Introduction}

Concrete is the most widely used construction material in the world. Ordinary Portland Cement (OPC) has been traditionally used as the binding agent for concrete. The worldwide consumption of concrete is estimated to increase due to the increase of infrastructure in countries such as India and China [1]. About 1 ton of carbon dioxide is released to the atmosphere during the manufacture of 1 ton of cement. Globally, the cement production contributes about $7 \%$ of the world's carbon dioxide [1]. The worldwide annual cement production is estimated as 2 billion tons at present and is expected to increase to 4 billion tons in 30 years from now [2]. In order to control the effect of global warming, it is necessary to reduce the emission of $\mathrm{CO}_{2}$ gas to the environment. The use of an alternative low-emission binding agent for concrete will help reduce the environmental impact of manufacturing of cement. Geopolymer is an alternative material that can act as a binding agent in concrete. The geopolymer binder contains no cement and thus will help enhance sustainability to construction industries.

Geopolymer Concrete. Geopolymer is a type of alumino-silicate product that shows good bonding properties. The geopolymer binders utilize a material such as fly ash or metakaolin as the 
source of Silicon and Aluminium for reaction by an alkali. In fly ash-based geopolymer binder, fly ash is reacted with an alkaline solution to create an alumino-silicate binder. Geopolymer binders are used together with aggregates to produce geopolymer concrete. The basic ingredients of fly ashbased geopolymer concrete are fly ash, alkali, fine aggregates and coarse aggregates. However, water and superplasticizer can be added to improve workability of the concrete. Current research [36] has shown potential use of geopolymer concrete as a construction material. Geopolymer concrete has the properties of high compressive strength, very little drying shrinkage, low creep, and good resistance to acid and sulphate attack. It was also shown that the structural performance of geopolymer concrete beams and columns is similar to that of OPC concrete members $[7,8]$.

Bond Strength of Concrete. The knowledge of bond behaviour between reinforcing steel and concrete is critical to the design of reinforced concrete structures. Bond behaviour is the interaction of the reinforcing bar with the concrete. This is described as the transfer of forces from the reinforcement to the surrounding concrete by adhesion between the bar and concrete, frictional force at the interface and bearing of the ribs of deformed bars against the concrete. The adhesion depends on the bar surface condition and the type of concrete. Bond resistance is governed by several factors such as compressive and tensile strengths of concrete, the concrete cover to the bar, confinement due to transverse reinforcement, surface condition of the bar and bar geometry [9-11]. Structural performance of reinforced concrete members depends on the bond between concrete and the reinforcement. The design provisions of reinforced concrete as a composite material utilize the bond strength between the two materials. The commonly used steel reinforcing bars have been developed for use with OPC concrete. Since geopolymer binder is chemically different from OPC, it is necessary to understand the bond properties between geopolymer concrete and steel reinforcement. This paper studied the bond strength of fly ash-based geopolymer concrete by using pull-out tests. A comparison is made between the bond strengths of geopolymer and OPC concretes with reinforcing steel.

\section{Experimental works}

Test Specimens. Pull-out test using beam-end specimens is used to evaluate the bond strength of a material because the test is relatively simple to conduct and it simulates the state of stresses in a beam [12, 13]. Geopolymer and OPC concrete beam-end specimens were manufactured and tested for pull out in accordance with ASTM 944 [14] to study the bond between concrete and reinforcing bars. The overall dimensions of the specimens were $250 \times 250 \times 600 \mathrm{~mm}$. The bars were de-bonded outside of the bonded length by using PVC pipes. The geometry of the specimens is shown in Fig. 1. The specific dimensions of each specimen of geopolymer and OPC concrete are given in Tables 1 and 2 respectively. In Tables 1 and 2, the specimens are designated by using the concrete batch used to cast them and a specimen number of that batch. For example, the designation of GPC2 S3 indicates that it is the specimen number 3 cast by using geopolymer concrete of batch 2 .

In order to prevent the specimens from failing by flexure or shear, as opposed to a bond failure, N16 and N12 bars were used as longitudinal and shear reinforcements respectively. The shear reinforcement was configured as two separate legs as shown in Fig. 1. They were not used in the form of closed ties to minimise confinement effect on concrete against splitting of the concrete during the pull-out test. The pull-out bars were either N20 or N24.

Materials. Low-calcium fly ash was used as the base material for geopolymer concrete. Locally available aggregates comprising $10 \mathrm{~mm}$ and $7 \mathrm{~mm}$ crushed granite-type coarse aggregates and fine sand were used. The aggregates were prepared to saturated-surface-dry (SSD) condition before mixing the concrete. The alkaline liquid used was a combination of sodium hydroxide and sodium silicate solutions. The sodium hydroxide solution was made by dissolving commercial grade $\mathrm{Na}(\mathrm{OH})$ solids in distilled water. The concentration of the $\mathrm{Na}(\mathrm{OH})$ solution was 14 Molars and it 
was prepared at least 24 hours prior to use. The sodium silicate solution had a chemical composition of $14.7 \% \mathrm{Na}_{2} \mathrm{O}, 29.4 \% \mathrm{SiO}_{2}$, and $55.9 \%$ water by mass. A commercially available naphthalene sulphonated super plasticizer and normal tap water were added to improve the workability of fresh geopolymer concrete.

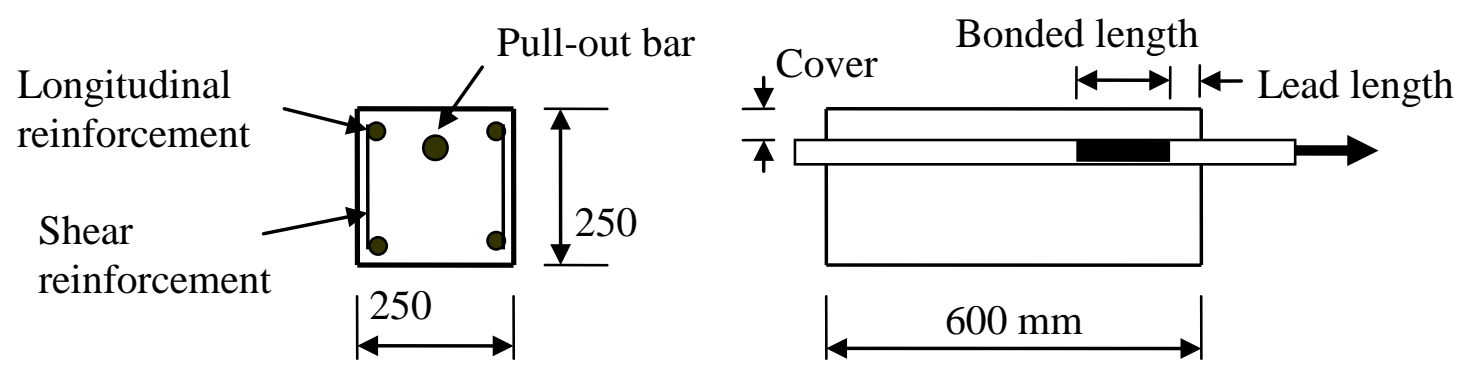

Fig. 1: Geometry of the beam-end specimens

Table 1: Specimen details and failure loads of geopolymer concrete specimens

\begin{tabular}{|c|c|c|c|c|c|c|c|}
\hline Specimen & $\begin{array}{l}\text { Compressive } \\
\text { strength, } f_{c} \\
(\mathrm{MPa})\end{array}$ & $\begin{array}{l}\text { Bar } \\
\text { diameter } \\
, d_{b} \\
(\mathrm{~mm})\end{array}$ & $\begin{array}{l}\text { Cover, } \\
c(\mathrm{~mm})\end{array}$ & $c / d_{b}$ & $\begin{array}{l}\text { Bonded } \\
\text { length, } \\
l_{d}(\mathrm{~mm})\end{array}$ & $\begin{array}{l}\text { Pull- } \\
\text { out } \\
\text { load, P } \\
(\mathrm{kN})\end{array}$ & $\begin{array}{l}\text { Bond } \\
\text { strength, } \\
u \text { (MPa) }\end{array}$ \\
\hline GPC1 S1 & \multirow[t]{6}{*}{25.5} & \multirow[t]{6}{*}{24} & 42 & 1.75 & 100 & 80 & 10.61 \\
\hline GPC1 S2 & & & 44 & 1.83 & 110 & 108 & 13.02 \\
\hline GPC1 S3 & & & 44 & 1.83 & 100 & 82 & 10.88 \\
\hline GPC1 S4 & & & 65 & 2.71 & 120 & 125 & 13.82 \\
\hline GPC1 S5 & & & 66 & 2.75 & 125 & 105 & 11.14 \\
\hline GPC1 S6 & & & 64 & 2.67 & 110 & 123 & 14.83 \\
\hline GPC2 S1 & \multirow[t]{6}{*}{29.7} & \multirow[t]{6}{*}{20} & 45 & 2.25 & 100 & 90 & 14.32 \\
\hline GPC2 S2 & & & 45 & 2.25 & 100 & 82 & 13.05 \\
\hline GPC2 S3 & & & 41 & 2.05 & 95 & 79 & 13.23 \\
\hline GPC2 S4 & & & 64 & 3.20 & 110 & 105 & 15.19 \\
\hline GPC2 S5 & & & 64 & 3.20 & 105 & 85 & 12.88 \\
\hline GPC2 S6 & & & 66 & 3.30 & 115 & 80 & 11.07 \\
\hline GPC3 S1 & \multirow[t]{6}{*}{32.5} & \multirow[t]{6}{*}{24} & 44 & 1.83 & 100 & 92 & 12.20 \\
\hline GPC3 S2 & & & 45 & 1.88 & 100 & 110 & 14.59 \\
\hline GPC3 S3 & & & 41 & 1.71 & 100 & 98 & 13.00 \\
\hline GPC3 S4 & & & 63 & 2.63 & 100 & 111 & 14.72 \\
\hline GPC3 S5 & & & 66 & 2.75 & 100 & 133 & 17.64 \\
\hline GPC3 S6 & & & 62 & 2.58 & 100 & 130 & 17.24 \\
\hline GPC4 S1 & \multirow[t]{6}{*}{39.5} & \multirow[t]{6}{*}{20} & 42 & 2.10 & 100 & 94 & 14.96 \\
\hline GPC4 S2 & & & 42 & 2.10 & 100 & 95 & 15.12 \\
\hline GPC4 S3 & & & 46 & 2.30 & 100 & 105 & 16.71 \\
\hline GPC4 S4 & & & 68 & 3.40 & 100 & 122 & 19.42 \\
\hline GPC4 S5 & & & 68 & 3.40 & 100 & 88 & 14.01 \\
\hline GPC4 S6 & & & 64 & 3.20 & 100 & 100 & 15.92 \\
\hline
\end{tabular}


The mixture proportions of the geopolymer and OPC concrete are given in Table 3. Specimens of batches GPC1 and GPC2 were cast using mixture 1 and specimens of batches GPC3 and GPC4 were cast using mixture 2. Mixtures 3, 4 and 5 were used to cast OPC specimens of batch OPC1, OPC2 and OPC3, and OPC4 respectively. Samples of steel bars were tested in the laboratory to obtain the actual yield and ultimate strengths. These results are given in Table 4.

Table 2: Specimen details and failure loads of OPC concrete specimens

\begin{tabular}{|c|c|c|c|c|c|c|c|}
\hline Specimen & $\begin{array}{l}\text { Compressive } \\
\text { strength, } f_{c} \\
(\mathrm{MPa})\end{array}$ & $\begin{array}{l}\text { Bar } \\
\text { diameter, } \\
d_{b}(\mathrm{~mm}) \\
\end{array}$ & $\begin{array}{l}\text { Cover, } \\
c(\mathrm{~mm})\end{array}$ & $c / d_{b}$ & $\begin{array}{l}\text { Bonded } \\
\text { length, } \\
l_{d}(\mathrm{~mm}) \\
\end{array}$ & $\begin{array}{l}\text { Pull-out } \\
\text { load, P } \\
(\mathrm{kN})\end{array}$ & $\begin{array}{l}\text { Bond } \\
\text { strength, } \\
u(\mathrm{MPa})\end{array}$ \\
\hline OPC1 S1 & \multirow[t]{6}{*}{42.3} & \multirow[t]{4}{*}{20} & 45 & 2.25 & 100 & 98 & 15.60 \\
\hline OPC1 S2 & & & 42 & 2.10 & 95 & 75 & 12.56 \\
\hline OPC1 S2 & & & 65 & 3.25 & 100 & 115 & 18.30 \\
\hline OPC1 S2 & & & 63 & 3.15 & 100 & 95 & 15.12 \\
\hline OPC1 S2 & & \multirow[t]{2}{*}{24} & 45 & 1.88 & 95 & 88 & 12.29 \\
\hline OPC1 S2 & & & 65 & 2.71 & 145 & 115 & 10.52 \\
\hline OPC2 S1 & \multirow[t]{6}{*}{37.2} & \multirow[t]{6}{*}{20} & 45 & 2.25 & 100 & 64 & 10.25 \\
\hline OPC2 S2 & & & 45 & 2.25 & 100 & 63 & 10.03 \\
\hline OPC2 S3 & & & 45 & 2.25 & 100 & 66 & 10.48 \\
\hline OPC2 S4 & & & 65 & 3.25 & 100 & 60 & 9.55 \\
\hline OPC2 S5 & & & 65 & 3.25 & 100 & 72 & 11.50 \\
\hline OPC2 S6 & & & 65 & 3.25 & 100 & 89 & 14.09 \\
\hline OPC3 S1 & \multirow[t]{6}{*}{34.0} & \multirow[t]{6}{*}{24} & 45 & 1.88 & 100 & 82 & 10.85 \\
\hline OPC3 S2 & & & 45 & 1.88 & 100 & 86 & 11.43 \\
\hline OPC3 S3 & & & 45 & 1.88 & 100 & 64 & 8.46 \\
\hline OPC3 S4 & & & 65 & 2.71 & 100 & 83 & 10.99 \\
\hline OPC3 S5 & & & 65 & 2.71 & 100 & 90 & 11.95 \\
\hline OPC3 S6 & & & 65 & 2.71 & 100 & 87 & 11.56 \\
\hline OPC4 S1 & \multirow[t]{6}{*}{55.3} & \multirow[t]{6}{*}{24} & 65 & 3.25 & 100 & 92 & 14.60 \\
\hline OPC4 S2 & & & 45 & 1.88 & 100 & 93 & 12.31 \\
\hline OPC4 S3 & & & 45 & 1.88 & 100 & 86 & 11.35 \\
\hline OPC4 S4 & & & 65 & 2.71 & 100 & 106 & 14.05 \\
\hline OPC4 S5 & & & 65 & 2.71 & 100 & 90 & 11.89 \\
\hline OPC4 S6 & & & 65 & 2.71 & 100 & 84 & 11.13 \\
\hline
\end{tabular}

Manufacturing and Testing of the Specimens. The manufacture and curing process of geopolymer concrete were based on earlier research [8]. The coarse aggregates $(10 \mathrm{~mm}$ and $7 \mathrm{~mm})$, sand and fly ash were first mixed dry in the laboratory pan mixer for about three minutes. At the end of this mixing, the alkaline liquid, together with the super plasticizer and the extra water were mixed together and added into the dry mixture. The mixing continued for another four minutes. After mixing, the fresh concrete was placed into the moulds.

The specimens were cast in a horizontal position and were vibrated with a standard mechanical vibrator. Standard $100 \mathrm{~mm} \times 200 \mathrm{~mm}$ cylinders were cast for compressive strength tests of the concrete. The geopolymer concrete specimens were placed inside the steam curing chamber after 
casting. The specimens were de-moulded after curing, and left in ambient conditions in the laboratory until the time of testing.

The beam-end specimens were tested for pull-out in accordance with the ASTM A944 Standard [14]. A schematic diagram of the load reaction configuration of the test rig is shown in Fig. 3 . The specimens were loaded using a hydraulic jack until failure. The reinforcing bar in the specimen was pulled at a loading rate of $8 \mathrm{kN}$ per minute. The specimens were tested within the ASTM A944 requirement that failure should not occur in the first three minutes.

Table 3: Mixture proportions of concrete $\left(\mathrm{kg} / \mathrm{m}^{3}\right)$

\begin{tabular}{|l|l|l|l|l|l|}
\hline Ingredients & \multicolumn{6}{|c|}{ Geopolymer concrete } & \multicolumn{2}{c|}{ OPC concrete } \\
\hline & Mixture 1 & Mixture 2 & Mixture 3 & Mixture 4 & Mixture 5 \\
\hline Cement & - & - & 420 & 357 & 424 \\
\hline Fly Ash & 408 & 408 & - & - & - \\
\hline 20mm aggregate & - & - & 560 & - & - \\
\hline 10mm aggregate & 555 & 555 & 540 & 458 & 456 \\
\hline 7mm aggregate & 647 & 647 & & 549 & 547 \\
\hline Sand & 647 & 647 & 740 & 760 & 697 \\
\hline Sodium hydroxide & 41 & 41 & - & - & - \\
\hline Sodium silicate & 103 & 103 & - & - & - \\
\hline Water & 24.3 & 14.95 & 130 & 225 & 225 \\
\hline Superplasticiser & 5.6 & 5.6 & 3 & - & - \\
\hline
\end{tabular}

Table 4: Properties of steel reinforcement

\begin{tabular}{|c|c|c|c|}
\hline Diameter (mm) & $\begin{array}{c}\text { Nominal area } \\
\left(\mathrm{mm}^{2}\right)\end{array}$ & $\begin{array}{c}\text { Yield strength } \\
(\mathrm{MPa})\end{array}$ & $\begin{array}{c}\text { Ultimate strength } \\
(\mathrm{MPa})\end{array}$ \\
\hline 12 & 110 & 531 & 672 \\
\hline 16 & 200 & 525 & 655 \\
\hline 20 & 310 & 570 & 662 \\
\hline 24 & 450 & 555 & 648 \\
\hline
\end{tabular}

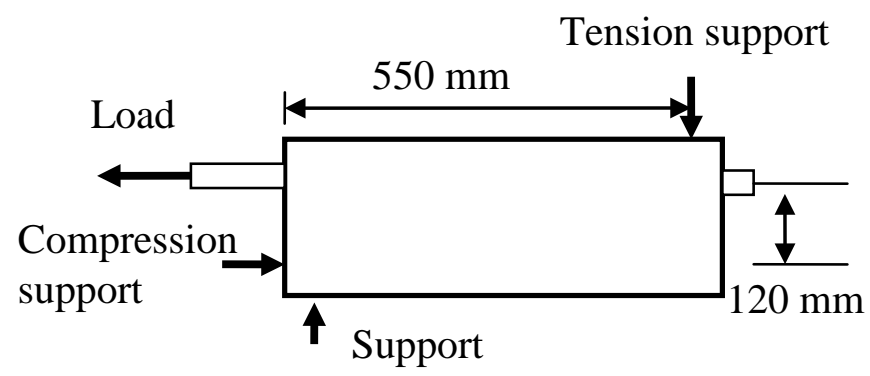

Fig. 2: Schematic diagram of test rig showing load-reaction configuration.

\section{Test Results and discussions}

All the specimens failed by splitting of the concrete in the region where the steel bar was bonded to the concrete as shown in Figs. 3 (a) and 3 (b). Concrete splitting crack patterns in the geopolymer concrete specimens were similar to those in the OPC concrete specimens. The failure occurred in a brittle manner in both types of concrete specimens. The pull-out load of each specimen is given in Tables 1 and 2.The test results in terms of bond strength and effect of different test parameters on bond strength are discussed in the following sections. 


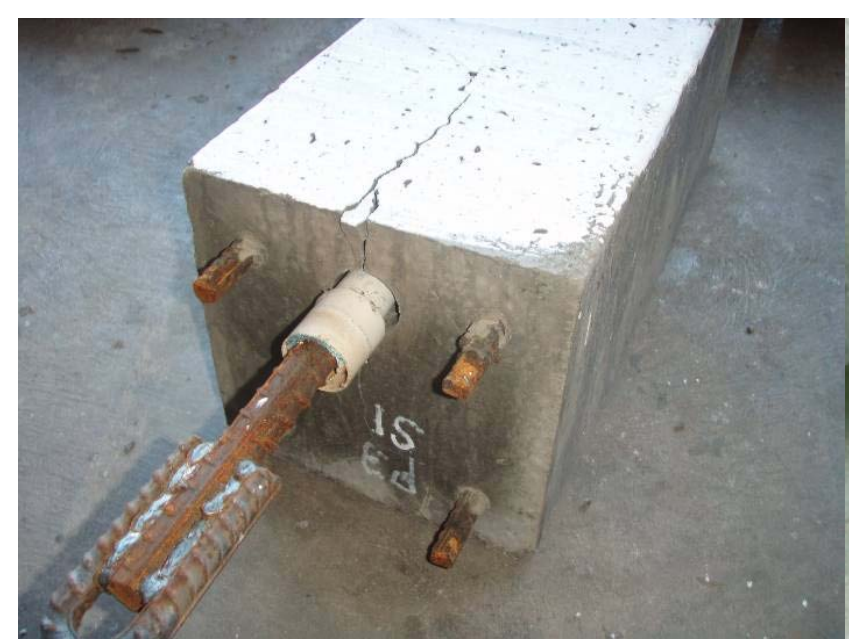

Fig. 3 (a) : Geopolymer concrete specimen

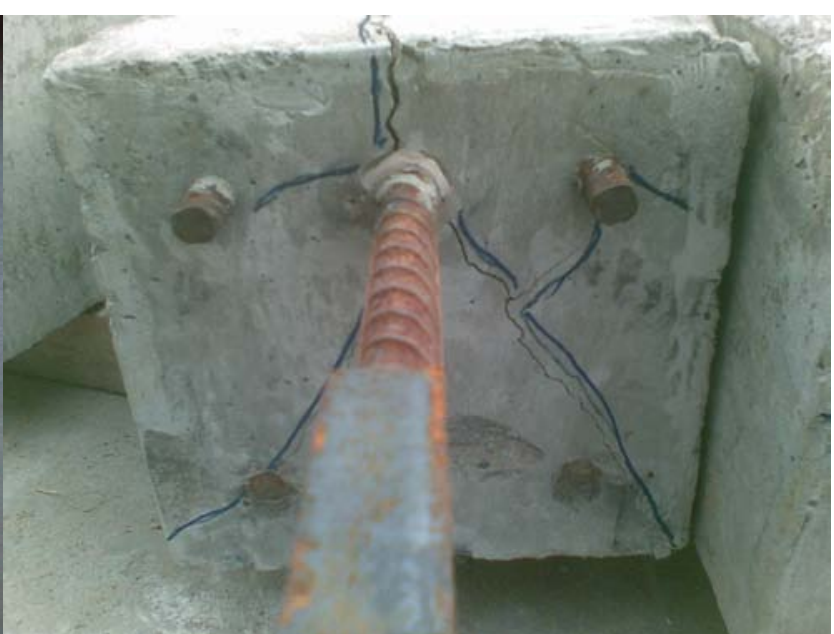

Fig. 3 (b) : OPC concrete specimen

Effect of parameters. The ultimate pull out failure load of each specimen was divided by the surface area of the bonded length of the bar to calculate the average bond strength. This bond strength is denoted by $u$ and the values are given in Tables 1 and 2. Since bond strength varies with the test parameters, the bond strength of geopolymer concrete is compared with that of OPC concrete for the same test parameter. The test parameters in this study are concrete compressive strength, bar diameter and concrete cover to the pull-out bar. The bond strength of the specimens with similar parameters are combined together to obtain a mean value of the bond strength for a test variable. These values are then plotted against the variable to compare its effect on the bond strength of OPC and geopolymer concrete.

The effect of concrete cover on bond strength for $20 \mathrm{~mm}$ and $24 \mathrm{~mm}$ diameter bars are shown in Figs. 4 and 5 respectively. Since the concrete compressive strength of the specimens were different, the bond strengths were normalized with respect to $f_{c}^{0.5}$. It can be seen that the normalized bond strength increased with the increase in concrete cover for both 20 and $24 \mathrm{~mm}$ bars. The trend is similar in both types of concrete. It is observed from these graphs that geopolymer concrete has higher bond strength than OPC for the same bar diameter and concrete cover.

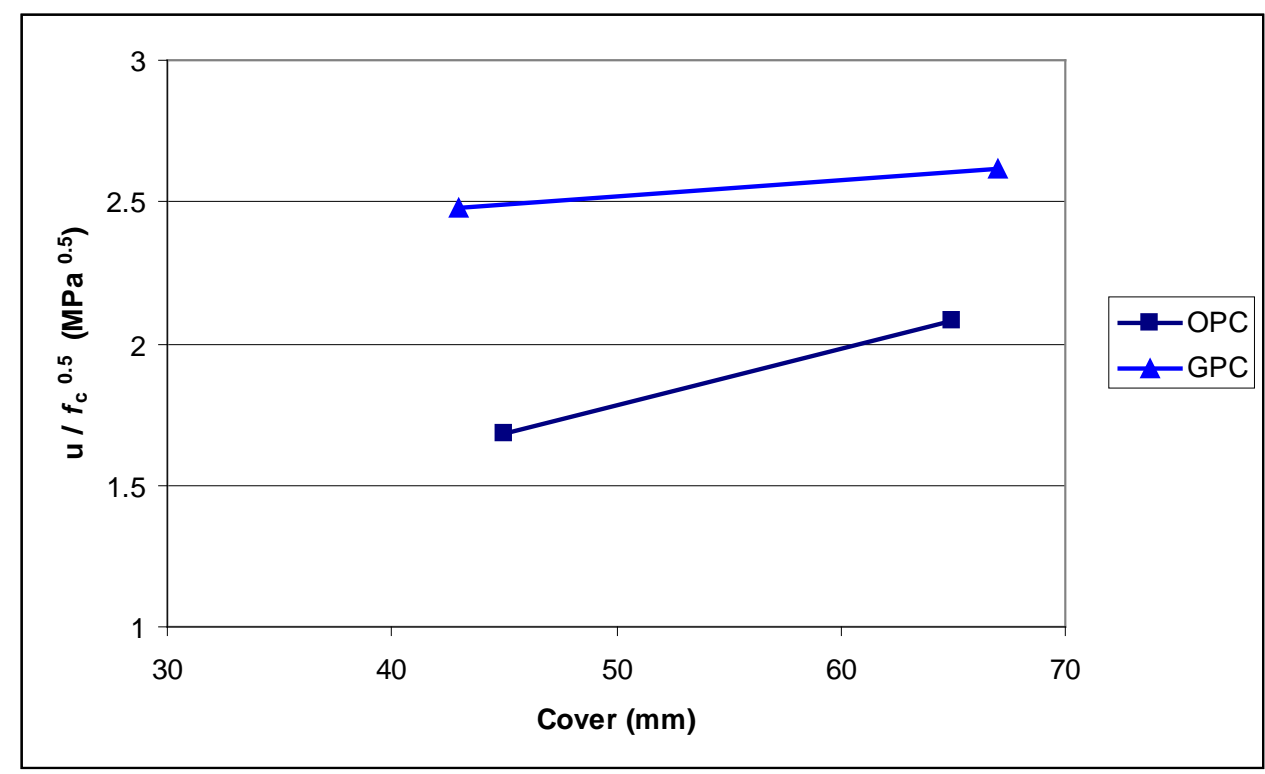

Fig. 4. Bond strength vs concrete cover for $20 \mathrm{~mm}$ bar 


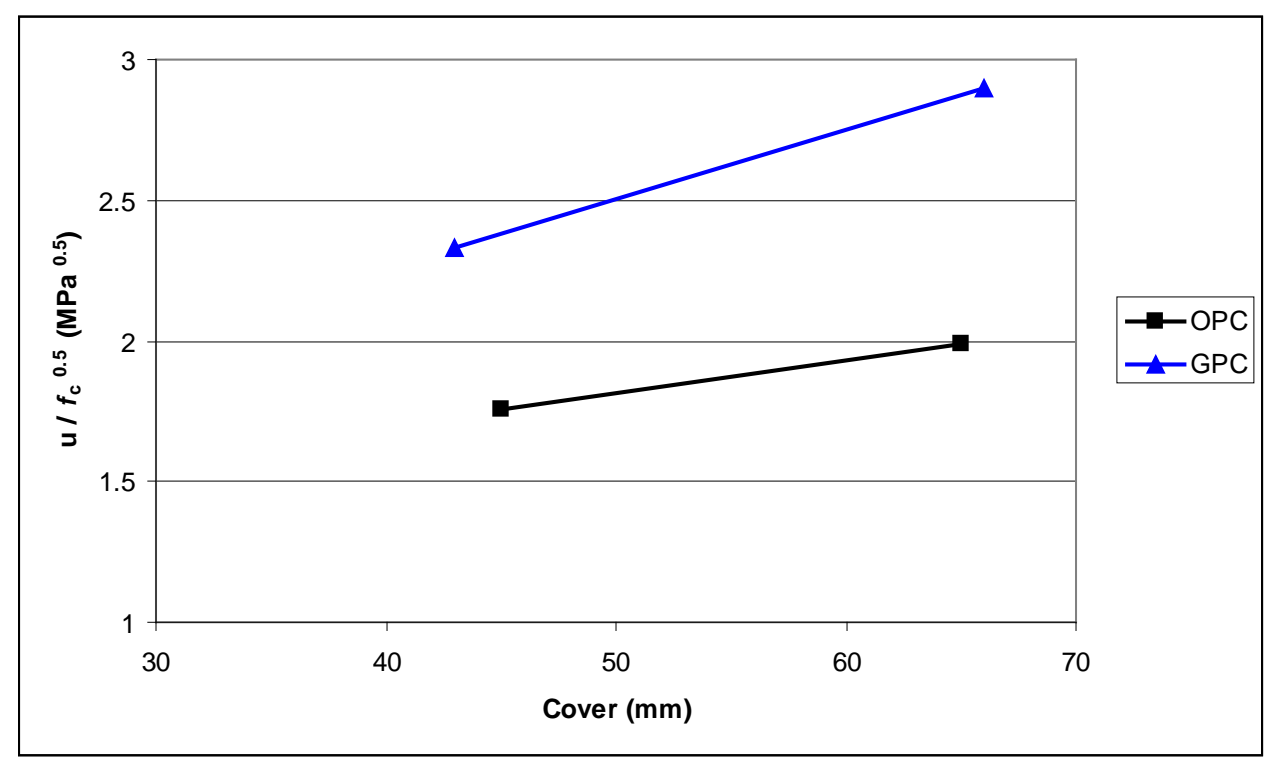

Fig. 5. Bond strength vs concrete cover for $24 \mathrm{~mm}$ bar

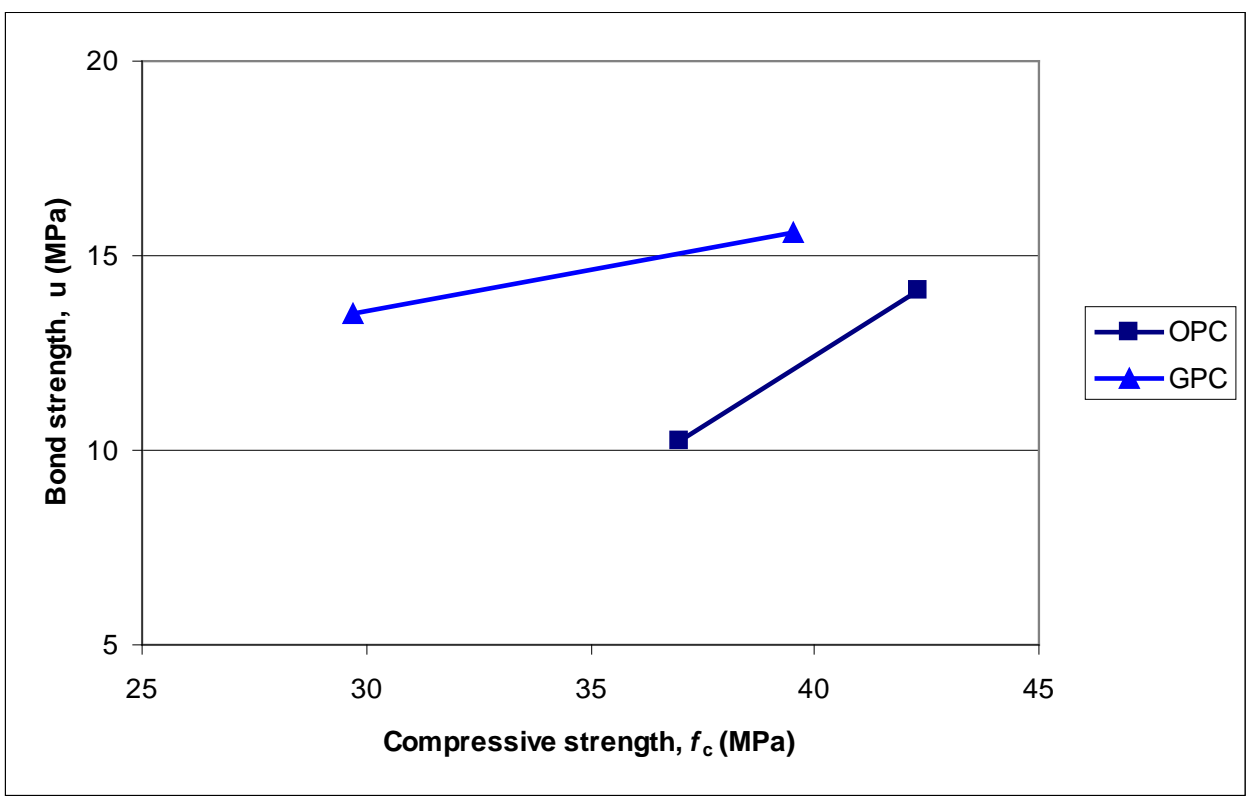

Fig. 6. Bond strength vs concrete compressive strength for $20 \mathrm{~mm}$ bar and $45 \mathrm{~mm}$ cover

Similarly, the effect of concrete compressive strength on bond strength of OPC and geopolymer concrete are shown in Figs. 6 and 7. Again, the specimens of similar compressive strength are combined together to obtain a mean value of the bond strength. It is seen from Figs. 6 and 7 that bond strength increased with the increase of compressive strength for both types of concrete. In both the figures, the trend line for geopolymer concrete is above the line for OPC concrete. This shows that the bond strength of geopolymer concrete is higher than that of OPC concrete for the same compressive strength.

Finally, the bond strength normalized with respect to $f_{c}^{0.5}$ are plotted against the concrete cover to bar diameter ratio $\left(c / d_{b}\right)$ and shown in Fig. 8. All the test specimens of OPC and geopolymer concrete are used to obtain mean values of normalised bond strength and $c / d_{b}$ ratio for this graph. It is seen from this graph that normalized bond strength increased with the increase of $c / d_{b}$ ratio in 
both types of concrete. The trend line for geopolymer concrete is similar to that of OPC. However the trend line of geopolymer concrete is above that of OPC concrete. Therefore, the test results show that bond strength of geopolymer concrete is generally higher than the line for OPC concrete. This suggests that the current bond strength equations [9, 10,12] for OPC concrete can be used for conservative prediction of the bond strength of geopolymer concrete.

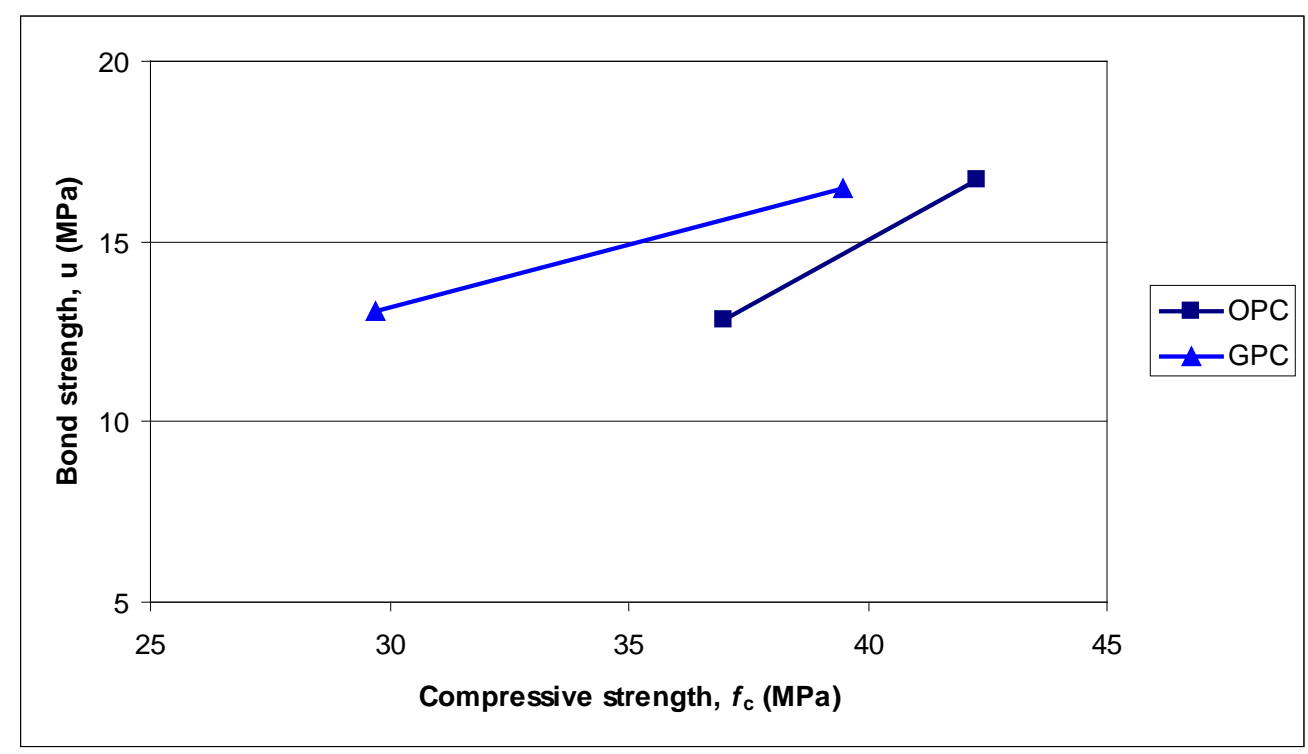

Fig. 7. Bond strength vs concrete compressive strength for $20 \mathrm{~mm}$ bar and $65 \mathrm{~mm}$ cover

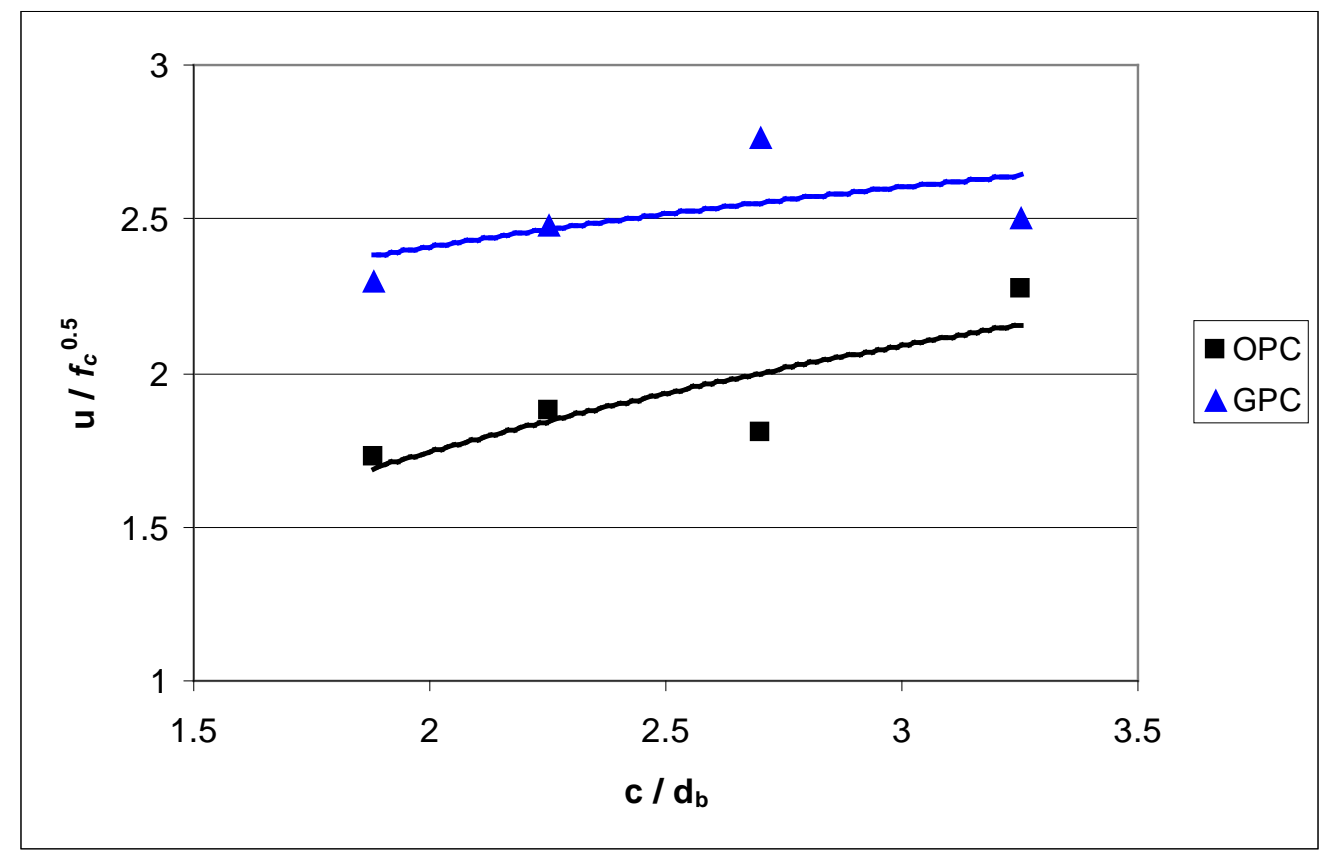

Fig. 8: Variation of bond strength with $c / d_{b}$ ratios.

\section{Conclusions}

Twenty-four geopolymer and 24 OPC concrete beam-end specimens were manufactured and tested for pull out in accordance with the ASTM 944 Standard. The test results were used to compare the 
bond strengths of geopolymer and OPC concretes with steel reinforcing bars. The following conclusions are drawn from the experimental results:

- Both geopolymer and OPC concrete specimens failed by splitting of concrete along the bonded length of the pull-out bar. Both types of concretes showed similar cracking patterns and brittle failure under the pull out load.

- In both types of concrete, bond strength increased with the increase of concrete cover and the concrete compressive strength.

- In both types of concrete, the bond strength normalized with respect to concrete compressive strength showed an increasing trend with the increase of concrete cover to bar diameter ratio.

- Generally, geopolymer concrete has higher bond strength than OPC concrete for the same test parameter. This suggests that the current bond strength equations for OPC concrete can be used for conservative prediction of the bond strength of geopolymer concrete.

\section{Acknowledgements}

The author gratefully acknowledges the contributions of Rocky Vasile, Aidan Grigg and the laboratory technicians of the Department of Civil Engineering, Curtin University of Technology to carry out the experimental works.

\section{References}

[1] P.K. Mehta: Concrete International Vol. 23, No. 6 (2001), p. 61-66.

[2] K. Sakai, in: Proceedings of the $6^{\text {th }}$ International Conference on Analytical Models and New Concepts in Concrete and Masonry Structures, Lodz, Poland, (2008), p. 139-155.

[3] B.V. Rangan: Indian Concrete Institute Journal (2006) October - December, p. 9-17.

[4] A.M. Fernandez-Jimenez, A. Palomo and C. Lopez-Hombrados: ACI Materials Journal Vol.103 (2006), p. $106-112$.

[5] D. Hardjito, S. E. Wallah, D.M.J. Sumajouw and B.V. Rangan: ACI Materials Journal, Vol. 101, (2004), p. 467-472.

[6] M. Sofi, J.S.J. van Deventer, P.A. Mendis and G.C. Lukey: Journal of Materials Science, Vol. 42 (2007), p. 3107-3116.

[7] P.K. Sarker: Materials and Structures Vol. 42 (2009), p. 715 - 724.

[8] D.M.J. Sumajouw, D. Hardjito, S.E. Wallah and B.V. Rangan: Journal of Material Science Vol. 42, No. 9 (2007), p. 3124-3130.

[9] M.R. Esfahani and B.V. Rangan: ACI Structural Journal Vol. 95, (1998). P. 272 - 280.

[10] C. O. Orangun, J. O. Jirsa and J. E. Breen: ACI Journal (1977) March, p. 114-122.

[11] D. Darwin, M.L. Tholen, E.K. Idun and J. Zuo: ACI Structural Journal Vol. 93 (1996), p. 347359.

[12] ACI Committee 408: Bond Development of Straight Reinforcing Bars in Tension (ACI 408R-

03) American Concrete Institute, Farmington Hills, USA(2003).

[13] T.M. Ahlborn and T. C. DenHartigh: Journal of Transportation research Board (2003), p. 8895.

[14] ASTM A 944-99: Standard Test Method for Comparing Bond Strength of Steel Reinforcing Bars to Concrete Beam-End Specimens, American Society for Testing and Materials Standard, West Conshohocken, US (1999). 